\title{
New Challenges and Countermeasures for China-Pakistan Relations
}

\author{
Nor Mamat \\ Department of Defence \& Strategic Studies, Maharishi Dayanand University, Rohtak, India
}

\section{Introduction}

In the world of contemporary international politics, SinoPak relations stand out as one of the few enduring friendship that have withstood the pressures of time and shifting geo- strategic conditions. The two countries established diplomatic ties in 1951 and have never looked back. In 2011, they commemorated (60) years of diplomatic ties, which was also designated as the ChinaPakistan Year of friendship. As staunch allies and strategic partners for the passt few decades, China and Pakistan have shared a friendship which has proved of great value in furtherance of their geo-political and strategic objectives. Their strong convergence in security interests has led to a multi-faceted strategic relationship which is reflected in a strong show of support for each other's positions across a wide spectrum of bilateral, regional and international issues.

\section{Chinese Nuclear Support and Supply to Pakistan}

One of the most important outcome of China-Pakistan strategic nexuss iss China's extensive support to Pakistan in building up its nuclear capabilities. China adopted an extremely supportive posture in the development of Pakistan's neuclear weapons and supplied with it a variety of nuclear products and services, ranging from uranium enrichment technology to research and power reactors.

Pakistan's missile development programme has been primarily carried out with the Chinese assistance and to some extent from North Korea after the United states imposed sanctions of China. Chinese missile assistance to Pakistan ranges from providing equipment, training to transferring the complete missiles.

China is today Pakistan's largest defense supplier. Pakistan has not only imported the maximum types and number of defence equipment from China but managed to build up its indigenous defense capability with the Chinese assistance. Chinese equipment turned out to be much cheaper as compared to equipment from the West and the Chinese sales were further facilitated by availability of credit from China on easy repayment terms. The navy also plans to manufacture and procure additional mine hunters, tankers, misssile and patrol boats. China has also confirmed the sale of six ship based medium sized Z9C helicopters to the Pakistan Navy.

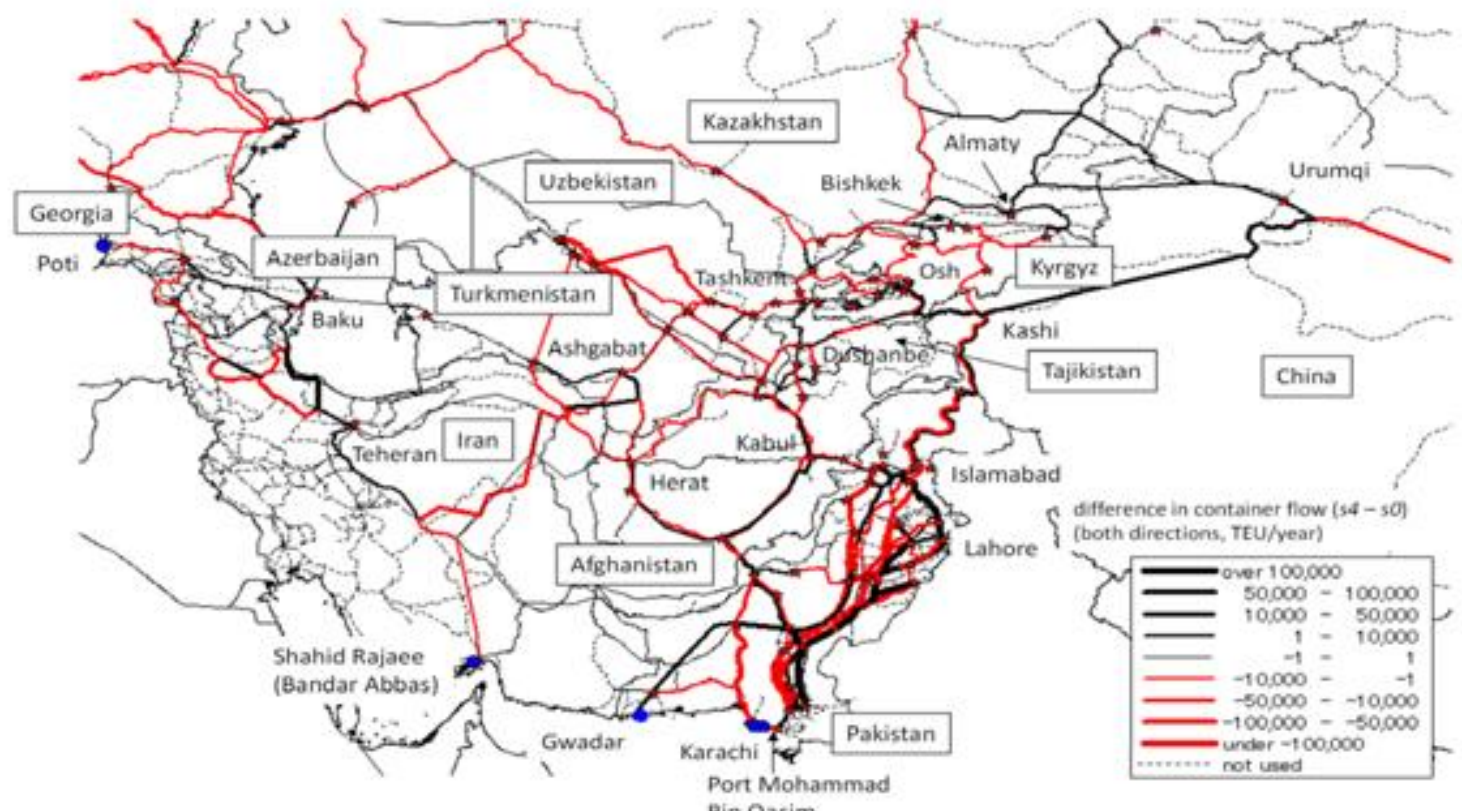

Source: Google Net

Development of the Gwadar Port

Gwadar has been development with the Chinese assistance and the primary project has been the construction of deep sea port expanding its maritime role 
and to allow the trade to and from the land locked Central Asia. More importantly, the port would have the conversion facilities to allow the movement of the natural gas for the Turkmenisstan- Afghanistan-Pakistan natural gas pipe line when completed. Gwadar offers the geoeconomic and geo-strategic pivot to China and Pakistan. It is strategically located on the south-western Coast of Pakistan between three increasingly important regions of the world; South Asia, Central Asia and oil-rich Middle East. Gwadar, which is overlooking the Gulf of Oman and the entrance to the Persion Gulf region is just 180 nautical miles from the straits of Hormuz. Thus Gwadar would eventually emerge as the key shipping hub providing mass trade to Central Asian Republics through Pakistan and China, and important naval base.

\section{Strategic important of CPEC}

The CPEC is strategically and economically important both for China and Pakistan. It will pave the way for China to access the Middle East and Africa from Gwadar Prot, enabling China to across the Indian Ocean and in setum China will support development projects in Pakistan to overcome the latter's energy crises and stabilizing its faltering economy. Additionally, the CPEC could serve as the drive for trade and economic integration between China, Pakistan, Iran, India, Afghanistan and Central Asian states provided the frosty political atmosphere between Pakistan, India and Afghanistan and to some extent Iran gets improved in the nearfuture.

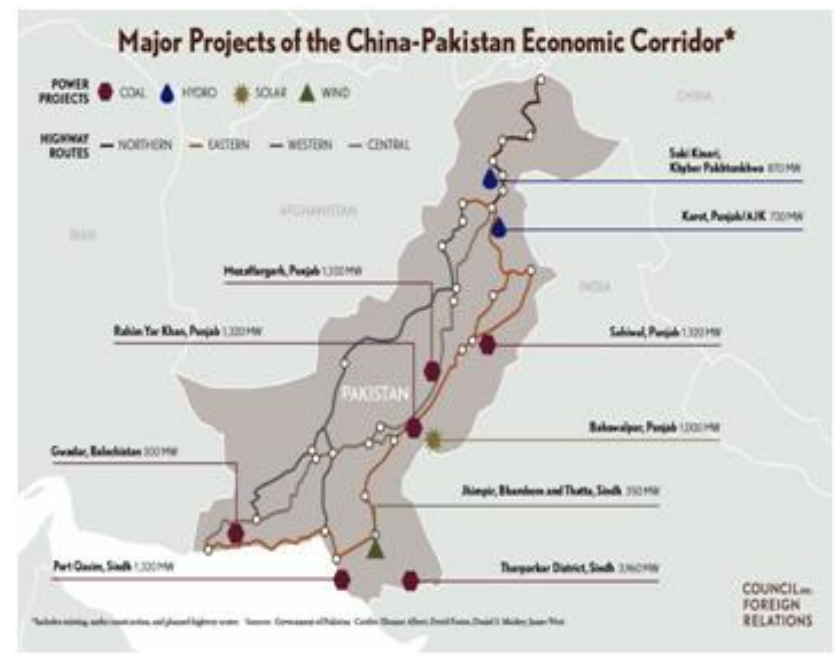

Source: Google Net

The CPEC connects China directly to the Indian Ocean and the region of the Middle East from the deep Gwadar Port reducing its existing dependence on the South China Seaa as the latter is becoming a contesting territory between various regional and global actors and can be choked any time by the completing powers in the AsiaPacific region. China currently transports $80 \%$ of its oil and energy needs through the Malacca strait and increasingly feels that its economic and energy security Interest in the region are under serious threats due to the escalation of tensions between China and the region and global players in South and East China sea. This is why China is looking for alternative viable transit routes both economically and security wise, the CPEC is the best choice for China linking it directly to the Indian ocean via

\section{Gwadar Port.}

\section{Implications for India}

The China and Pakistan military threats have been in existence for the last half a century or so and stand manifested in terms of armed conflicts with India. However, these two military threats to India acquire more simister contours when viewed from the prism of the meteoric military rise of China and a sinking Pakistan on the edge of an abyss over which it could hurtle any time. What all this amounts to is that with a rising China and a sinking Pakistan the propensity of their conflict with India becomes that much higher.

\section{Conclusion}

The growing China-Pak relation can have larger implications for India. Presence of Chinese navy in the Indian Ocean which is facilitated by Pakistan poses a serious that to India's security in the region. With China trying to dominate the South Asian sphere by following its policy "String of Pearls" so as to reduce India's shpere of influence and trying to secure the vital energy routes, India will have to strategize, devise and trigger its military operations following the "Necklace of diamonds" policy as a counter measure to hold on the and amplify itsss sphere of influence.

Also the China-Pak axis can cause trouble to the much establish influence India has in Afghanistan, with the new Ghani government having its tilt towards Pakistan in a bid to secure peace in his country. A reduced footprint for Indian intelligence in Afghanistan could be on the cards as well. The transfer of Chinese defense technology doesn't pose as a warning only to India to upkeep its security but also the other non-proliferation regimes are at a risk. Moreover, with China trying to flood Chinese in Tibet so as to make it loose its cultural identity and looming with its own Dalai Lama establishment, India might lose its only baragaining chip to China. It is crucial for India to crate stakeholders in China in order to gain some discrete influence and have a say in its policies.

\section{References}

[1] Upadhyay, Col, MD, Sino-Pak Nexus and Implication for India, Vij Books India Pvt. Ltd. New Delhi, 2015

[2] Rajan, Dr. Ravi Armed conflict and security in South Asia, Sumit Enterprises, New Delhi, 2012

[3] Adhikari, Shekhar (Ed.) South Asia : Traditional and Non-Traditional Security Threats, Pentagon Press, New Delhi, 2015

[4] B. Pakistan's Nuclear Weapons, Routledge, London, 2009

[5] Chandrashekhar, S, An Assessment ofPakistan's Ballistic Missile Programme : Technical and Strategic Capabilities, NIAS study, 2006

[6] Haq. D. N., Sixty years of Pak-China Diplomatic Relations (1951-2011) Islamabad Policy Research Institute, 2011

[7] Harpence, M., The Economic Dimension of SinoPakistan Relations : An Overview Journal of 
Contemporary China, 2011

[8] Pant, H.V., The Pakistan Thorn in China- India-U.S. Relations. The Washington Quarterly 2012

[9] Siddiqui, R.A., China's Evolving Posture in South Asia : Some Reflection, IPRI Journal 2014

[10] Rezual H. Laskar, India, Pakistan Spar Over Economic Corridor Passing Through POK, Hindustan Times, June 1, 15. http://www/hindustantimes.com/india-news/indiapakistan-spar-over-46-billion-pak-china-economiccorridor-passing-through- pok/article-1353486.aspx

[11] Malik, Mohan, 'The China-Pakistan Nexus' in John wilson ed Pakistan : The struggle within, Perason Longman, Delhi, 2009

[12] Small, Andrew, The China- Pakistan Axis ; Asia's New Geopolitics, C Hurst \& Co publishers Ltd. New Delhi, 2015

[13] Sharma, Ritika, India and the Dynamics of the World Politics, Pearson Education India, New Delhi, 2011

[14] Roy, Meenu, Indian and Her Sub-Continent Neighbours : New Pattern of Relationship, Deep and Deep Publication, New Delhi, 2010 